\title{
Hematopoietic transcription factors and differential cofactor binding regulate PRKACB isoform expression
}

\author{
Olga N. Kuvardina ${ }^{1}$, Stefanie Herkt ${ }^{1}$, Annekarin Meyer ${ }^{1}$, Lucas Schneider $^{1}$, Jasmin \\ Yillah'2 ${ }^{2}$ Nicole Kohrs ${ }^{2}$, Halvard Bonig ${ }^{1}$, Erhard Seifried ${ }^{1}$, Carsten Müller-Tidow ${ }^{3}$ \\ and Jörn Lausen ${ }^{1}$ \\ ${ }^{1}$ Institute for Transfusion Medicine and Immunohematology, Johann-Wolfgang-Goethe University and German Red Cross \\ Blood Service, Frankfurt am Main, Germany \\ ${ }^{2}$ Georg-Speyer-Haus, Institute for Tumorbiology and experimental Therapy, Frankfurt, Germany \\ ${ }^{3}$ Department of Internal Medicine V, Hematology, Oncology and Rheumatology, University of Heidelberg, Heidelberg, Germany \\ Correspondence to: Jörn Lausen, email: j.lausen@blutspende.de
} Keywords: gene regulation, transcription factors, epigenetics, hematopoiesis, oncogenes Received: November 09, $2016 \quad$ Accepted: March 27, 2017 Published: April 24, 2017

Copyright: Kuvardina et al. This is an open-access article distributed under the terms of the Creative Commons Attribution License 3.0 (CC BY 3.0), which permits unrestricted use, distribution, and reproduction in any medium, provided the original author and source are credited.

\section{ABSTRACT}

Hematopoietic differentiation is controlled by key transcription factors, which regulate stem cell functions and differentiation. TAL1 is a central transcription factor for hematopoietic stem cell development in the embryo and for gene regulation during erythroid/megakaryocytic differentiation. Knowledge of the target genes controlled by a given transcription factor is important to understand its contribution to normal development and disease. To uncover direct target genes of TAL1 we used high affinity streptavidin/biotin-based chromatin precipitation (Strep-CP) followed by Strep-CP on ChIP analysis using ChIP promoter arrays. We identified 451 TAL1 target genes in $\mathrm{K562}$ cells. Furthermore, we analysed the regulation of one of these genes, the catalytic subunit beta of protein kinase A (PRKACB), during megakaryopoiesis of $\mathrm{K562}$ and primary human CD34+ stem cell/progenitor cells. We found that TAL1 together with hematopoietic transcription factors RUNX1 and GATA1 binds to the promoter of the isoform 3 of PRKACB (CB3). During megakaryocytic differentiation a coactivator complex on the $C \beta 3$ promoter, which includes WDR5 and p300, is replaced with a corepressor complex. In this manner, activating chromatin modifications are removed and expression of the PRKACB-CB3 isoform during megakaryocytic differentiation is reduced. Our data uncover a role of the TAL1 complex in controlling differential isoform expression of PRKACB. These results reveal a novel function of TAL1, RUNX1 and GATA1 in the transcriptional control of protein kinase A activity, with implications for cellular signalling control during differentiation and disease.

\section{INTRODUCTION}

During hematopoiesis mature blood cells are generated from hematopoietic stem cells (HSC), which reside in the bone marrow. HSCs produce progeny of intermediate repopulation potential, the progenitor cells. Meanwhile, maintaining a finite stable pool of stem cells by self-renewal. Hematopoietic progenitor cells undergo further differentiation into mature cells of the lymphoid and myeloid branches. This differentiation process is influenced by internal and external signalling events and by the activity of transcription factors at the endpoint of these signalling pathways [1]. Transcription factors execute differentiation programs by activating cell type specific gene expression. The important function of transcription factors in hematopoiesis is reflected by the fact that loss of function of specific transcription factors can obliterate stem cell function and/or lead to altered lineage differentiation [2]. In humans, mutations and chromosomal translocations of transcription factors have been identified as a cause of 
leukemia and lymphoma [3]. Thus, extensive research in the field is aimed to understand the function of hematopoietic transcription factors in health and disease.

TAL1 (T-cell acute lymphocytic leukemia 1) is one of the central transcription factors for HSC development in the embryo and for gene regulation during erythroid/ megakaryocytic differentiation [4-8]. Furthermore, aberrant expression of TAL1 in the T-cell compartment caused by chromosomal translocations leads to T-lineage acute lymphoblastic leukemia (T-ALL) [9-11]. Considerable progress has been made to better understand the function of TAL1 by the identification of TAL1 target genes [12-14]. Recently, we discovered that TAL1 interacts with RUNX1 (RUNT-related transcription factor 1) on erythroid genes in progenitor cells [15-17]. However, although TAL1 is readily expressed in erythrocyte/megakaryocyte progenitors and in the megakaryocytic lineage [18], little is known about the function of TAL1 in megakaryocytes.

To examine the role of TAL1 during megakaryopoiesis, we performed chromatin precipitation and promoter ChIP array analysis to define megakaryocytic target genes of TAL1. We identified a number of TAL1 target genes, which had recently been associated with megakaryocytic differentiation of K562 cells [19]. In particular, we found that TAL1 is a regulator of the catalytic subunit beta of protein kinase A (PRKACB). PKA is a cytoplasmatic holoenzyme consistent of two catalytic and two regulatory subunits. Upon generation of cyclic AMP (cAMP) e.g. upon hormone stimulus, cAMP binds to the regulatory units of PKA $[20,21]$. This triggers dissociation of the regulatory and catalytic subunits. The catalytic subunits $(C \alpha, C \beta, C \gamma)$ phosphorylate substrates on serine and threonine residues [22]. Substrates include transcription factors, which have a role in differentiation and proliferation $[20,23]$. The $P R K A C B$ gene encodes the beta subunit of PKA. There are four isoforms of $P R K A C B$ described and in addition several splice variants, each of the isoforms has a separate promoter and a distinct $\mathrm{N}$-terminus [24, 25].

We found that TAL1 binds to the promoter of isoform 3 of PRKACB (CB3) together with the hematopoietic transcription factors RUNX1 and GATA1 (GATA-binding protein 1). Our data show that GATA1 acts as an activator of $C \beta 3$ isoform expression. Furthermore, RUNX1 and TAL1 contribute to the repression of $C \beta 3$ expression. Repression of $C \beta 3$ during megakaryocytic differentiation is triggered by the loss of coactivator binding and by recruitment of corepressor proteins to the $C \beta 3$ promoter.

\section{RESULTS}

\section{Identification of TAL1 target genes}

To identify TAL1 target genes, we made use of K562 cells. These cells exhibit properties of erythrocyte/ megakaryocyte progenitor cells as they can be induced towards the erythroid or megakaryocytic lineage [26-28].
We established a BirA-TAL1 K562 cell line expressing TAL1 fused to a 12 amino acid BirA-tag, which is biotinylated within the cells by a coexpressed BirA-ligase [14]. With this system biotinylated BirA-tagged TAL1 protein can be purified with streptavidin coated beads $[16$, 29]. Alternatively, the BirA-tag/streptavidin interaction can be used for chromatin immunoprecipitation (ChIP), which has the advantage of high affinity without use of an antibody [14, 30, 31]. By streptavidin based chromatin precipitation (Strep-CP) we could enrich promoter DNA of the well-established TAL1 target gene glycophorin A (GYPA) 10-fold better than with a TAL1 antibody, despite more stringent washing conditions with Strep-CP (Figure 1A, 1B).

To identify novel TAL1 target genes, we performed 'Strep-CP on ChIP' analysis using ChIP-arrays with 12.000 human promoter regions spotted as oligonucleotides (Figure 1C) [32]. 451 promoter sites with TAL1 binding were identified at genes (Supplementary File 1). When we applied GO-term analysis using DAVID [33, 34] we found that genes involved in biological functions related to transcriptional regulation, inflammatory responses, apoptotic processes, negative regulation of cell proliferation, response to drugs and immune response were enriched in our dataset (Figure 1D, GO term IDs are given in Supplementary Figure 1). For further analysis we chose nine genes, which have a role in human disease. These genes also displayed changes in gene expression upon induction of megakaryocytic differentiation of K562 cells [19]. To verify TAL1 target genes, TAL1 binding was tested in wild type K562 cells with a standard ChIP using a TAL1 specific antibody and primers specific for the identified regions (Figure 1E). ChIP against the established TAL1 target GYPA served as positive control and ChIP against exon 6 of GAPDH as negative control. We confirmed TAL1 binding to regulatory elements of $I L$ 19 (interleukin 19), GCC2 (GRIP and coiled-coil domain containing 2), PCBD2 (pterin-4 alpha-carbinolamine dehydratase 2), Dicer, PIP5K1a (phosphatidylinositol-4phosphate 5-kinase, type I, alpha), $C B L$ (casitas B-lineage lymphoma), $P R K A C B$ (protein kinase, cAMP-dependent, catalytic, beta), WNT9 (wingless-type MMTV integration site family, member 9) and CTNNB1 (catenin (cadherinassociated protein) beta 1) (Figure 1E).

\section{Analysis of TAL1 target gene expression}

To evaluate which of the genes bound by TAL1 respond to changes in TAL1 expression, we performed knockdown of TAL1 by shRNA in K562 cells. We found that $I L-19$, Dicer and PRKACB were upregulated, whereas WNT9 was downregulated upon Tall knockdown. The other genes did not exhibit expression changes upon TAL1 knockdown under these conditions (Figure 2A). This observation is in line with the notion that TAL1 can serve as an activator or repressor of gene expression in a cell- and 

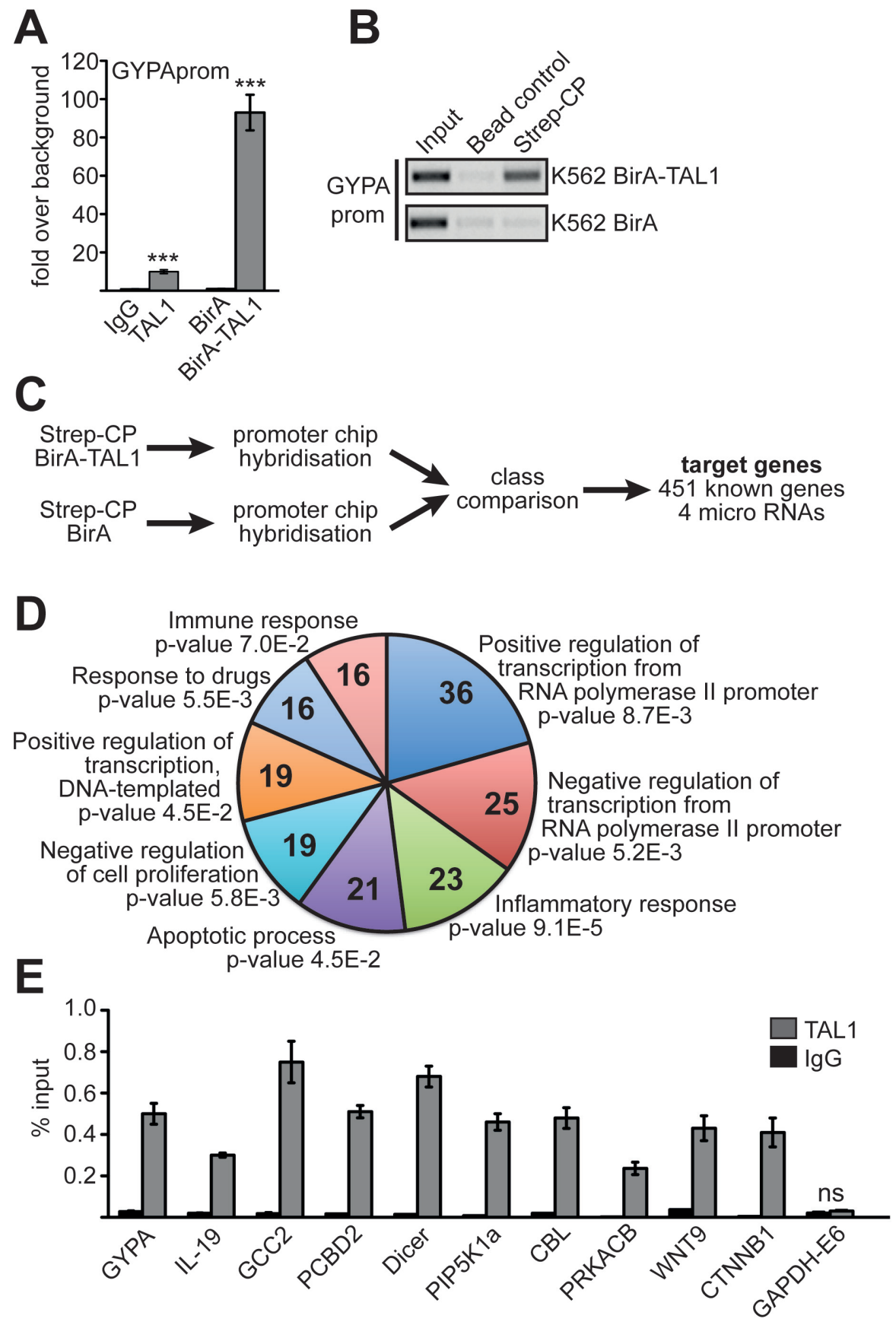

Figure 1: Identification of TAL1 target genes. (A) Comparison of a chromatin immunoprecipitation (ChIP) using a TAL1 specific antibody and streptavidin/biotin chromatin precipitation (Strep-CP). ChIP-PCR is performed with primers specific for the promoter of the known TAL1 target GYPA. Values are given as fold over IgG background or as fold over background using a BirA-ligase only expressing K562 cell line (BirA) as control, respectively. Error bars represent the standard deviation from three independent evaluations. The P values were calculated using Student's t-test. *** $\mathrm{P}<.001$. (B) Control Strep-CP from K562 cells harboring the BirA-ligase and BirA-TAL1 (upper part) compared to cells with BirA-ligase only (lower part). A precipitation with magnetic IgG beads was included as a negative control. ChIP-PCR was performed against GYPA promoter (GYPAprom). The PCR product was analysed on an agarose gel. The color inverted image of the gel is shown. (C) Flow chart showing the identification of TAL1 target genes by Strep-CP and ChIP analysis. (D) GO-term analysis using DAVID (DAVID Bioinformatics Resources 6.8) $[33,34]$ of the 451 potential TAL1 target genes. Shown are the eight GOterms with the highest number of genes and the $\mathrm{P}$ values are given. Parameters for GO-term biological process (GO-BP direct) were default settings (with modified Fisher exact P value, EASE, set as 0.1). (E) Verification of TAL1 target genes found by Strep-CP using a standard ChIP with anti-TAL1 antibody. GYPA promoter was used as positive control and exon 6 of GAPDH (GAPDH-E6) as negative control. ChIP-PCR was performed with specific primer pairs against the given loci. Values are given as percent enrichment compared to the input. Error bars represent the standard deviation of two independent evaluations performed in duplicate. The $\mathrm{P}$ values for all verification ChIP experiments were at least $\mathrm{P}<.05$ according to Student's t-test. 
promoter-dependent context. PRKACB is an enzymatic subunit of the protein kinase A complex (PKA). PKA is a very important signalling molecule, which influences almost all aspects of cellular differentiation through phosphorylation of transcription factors (Figure 2B).

PRKACB is involved in PKA-signalling, which is a central signalling pathway within cells. Furthermore, PKA-signalling influences the function of TAL1 [35, 36]. Thus, the potential involvement of TAL1 in regulating PRKACB opens the possibility of a reciprocal regulation between PKA-signalling and the functional regulation of
TAL1. For this reason we further studied the influence of TAL1 on PRKACB expression. To further investigate $P R K A C B$ expression at the erythroid/megakaryocytic branching point, we used primary human CD34+ progenitor cells. We differentiated these cells towards the erythroid or megakaryocytic lineage [14, 37]. Overall expression of $P R K A C B$ was not altered during erythroid differentiation (Figure $2 \mathrm{C}$ ) and increased during megakaryocytic differentiation (Figure 2D). Similarly, megakaryocytic differentiation of K562 cells led to an increased PRKACB mRNA (Figure 2E) [19].
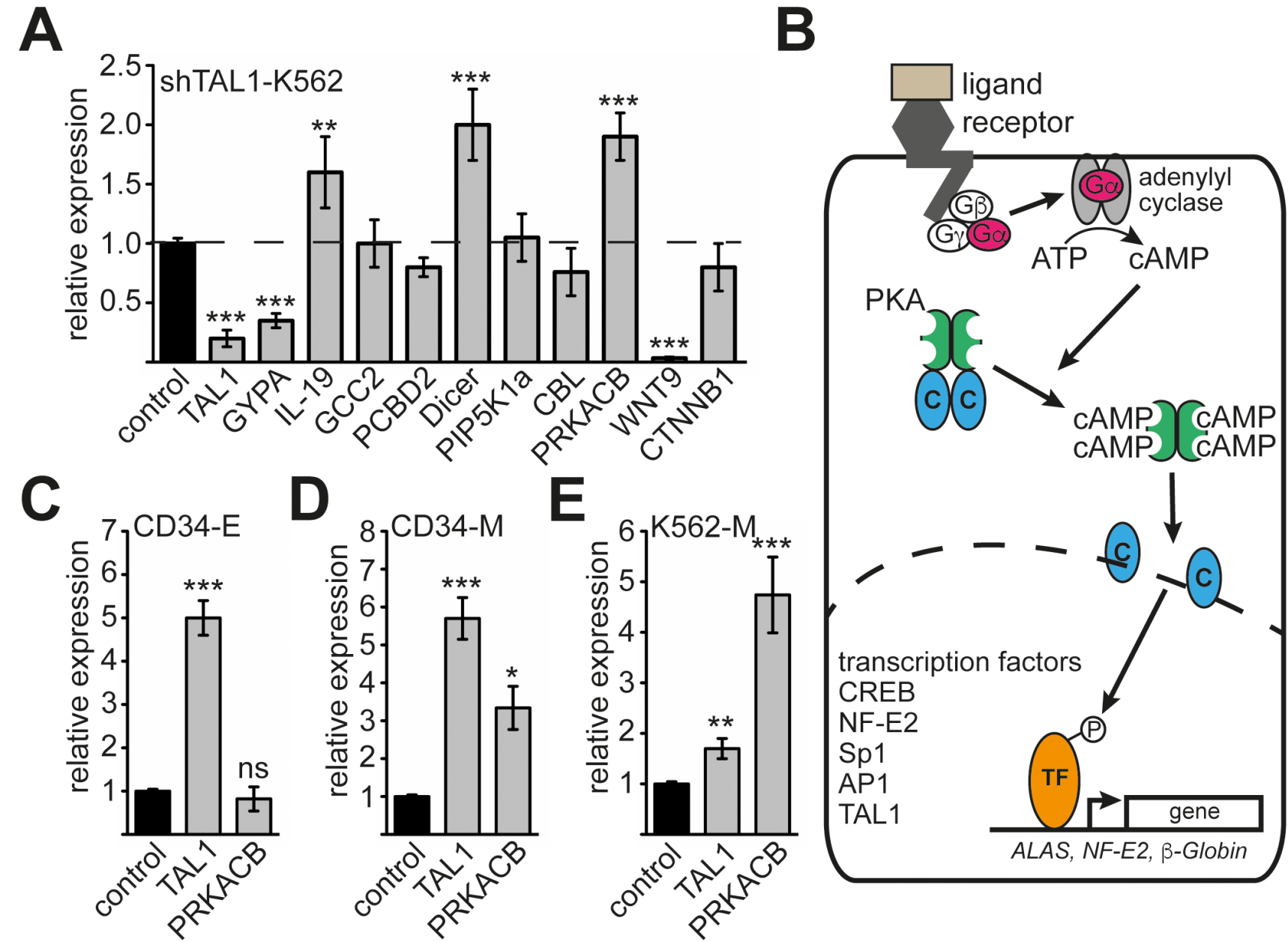

Figure 2: Analysis of PRKACB isoform expression during differentiation. (A) Expression of nine selected TAL1 target genes upon TAL1 knockdown. TAL1 knockdown was performed by shRNA in K562 cells and the expression of the given genes measured by qRT-PCR. The well-established TAL1 target gene GYPA was included as a positive control. Data are shown as relative expression compared to values gathered upon transduction of a non-targeting shRNA vector (labelled as control). Expression of GAPDH served as internal control for normalization of gene expression. (B) Schematic presentation of protein kinase A (PKA) function. Upon activation of G-protein receptor the $\mathrm{G} \alpha$ subunit activates an adenylyl cyclase, which produces cAMP. Binding of cAMP to the regulatory units of PKA sets free the catalytic subunits, which translocate into the nucleus. In the nucleus several transcription factors are phosphorylated. Examples are CREB, NF-E2, Sp1, AP1 and TAL1. Some of these transcription factors are able to regulate erythroid genes, such as ALAS, NF-E2 and $\beta$-globin. (C) Expression of TAL1 and PRKACB during erythroid differentiation of primary human CD34+ progenitor cells. (D) Expression of TAL1 and $P R K A C B$ during megakaryocytic differentiation of primary human CD34+ progenitor cells. (E) Expression of TAL1 and PRKACB during megakaryocytic differentiation of K562 cells. (C-E) Values are shown as relative expression compared to undifferentiated cells labelled as control. Expression of GAPDH served as internal control for normalization of gene expression. Error bars represent the standard deviation of qRT-PCR evaluations of three independent experiments measured in duplicates. The P values were calculated using Student's t-test. $* * \mathrm{P}<.01 ; * * * \mathrm{P}<.001$. 


\section{Isoform 3 of $P R K A C B$ is down regulated during megakaryocytic differentiation}

The $P R K A C B$ gene encodes the catalytic beta subunit of PKA. Four isoforms of PRKACB have been described in addition to several splice variants [24]; each of the isoforms has a separate promoter and a distinct N-terminus (Figure 3A). Based on the 'Strep-CP on ChIP' analysis data, the TAL1 binding site is located 5' of the $P R K A C B$ isoform 3 (CB3) (Figure 3A). To analyse the role of TAL1 on C $\beta 3$ expression control, we examined expression of the different isoforms using isoform specific PCR primer and semiquantitative RT-PCR. Interestingly, upon megakaryocytic differentiation of hCD34+ or K562 cells expression of the PRKACB isoform $1(C \beta 1)$ was increased, whereas the $C \beta 3$ isoform was decreased (Figure $3 \mathrm{~B})$. The decreased expression of the $C \beta 3$ isoform upon megakaryocytic differentiation was verified in $\mathrm{hCD} 34+$ and K562 cells using qRT-PCR (Figure 3C-3D).

\section{Analysis of the $P R K A C B-\beta 3$ promoter}

Using TESS (transcription element search system) software [38] we analysed the $5^{\prime}$ 'region of the $C \beta 3$ isoform and identified several potential binding sites for TAL1 (E-Boxes) 5' of the transcription start. Furthermore, RUNX1 and GATA1 sites were present in this area (Figure $4 \mathrm{~A})$. We cloned the 5'-region including the 5'-UTR of $C \beta 3$ into the pGL4 luciferase reporter gene vector for promoter analysis. Subsequently, we cotransfected the promoter reporter construct with TAL1, GATA1 or RUNX1 into HEK293 cells. Cotransfection of TAL1 with the promoter construct did not influence promoter activity, whereas GATA1 markedly activated the promoter (Figure 4B). Interestingly, RUNX1 repressed $C \beta 3$ promoter activity. Cotransfection experiments revealed that RUNX1 inhibits the activity of the $C \beta 3$ promoter even in the presence of GATA1 or TAL1 (Figure 4B). The expression constructs were verified by western blot (Figure 4C). Subsequently, we performed a reporter gene assay in K562 cells and detected an activating effect of GATA1 on reporter gene activity and a repressive effect of RUNX1 (Figure 4D). Furthermore, cotransfection of knockdown constructs against TAL1 and RUNX1 increased $C \beta 3$ promoter activity. In contrast, GATA1 knockdown resulted in decreased activity (Figure 4E). These data indicate that GATA1 activates the PRKACB $\beta 3$ promoter, whereas RUNX1 is a repressor of the PRKACB $\beta 3$ isoform.
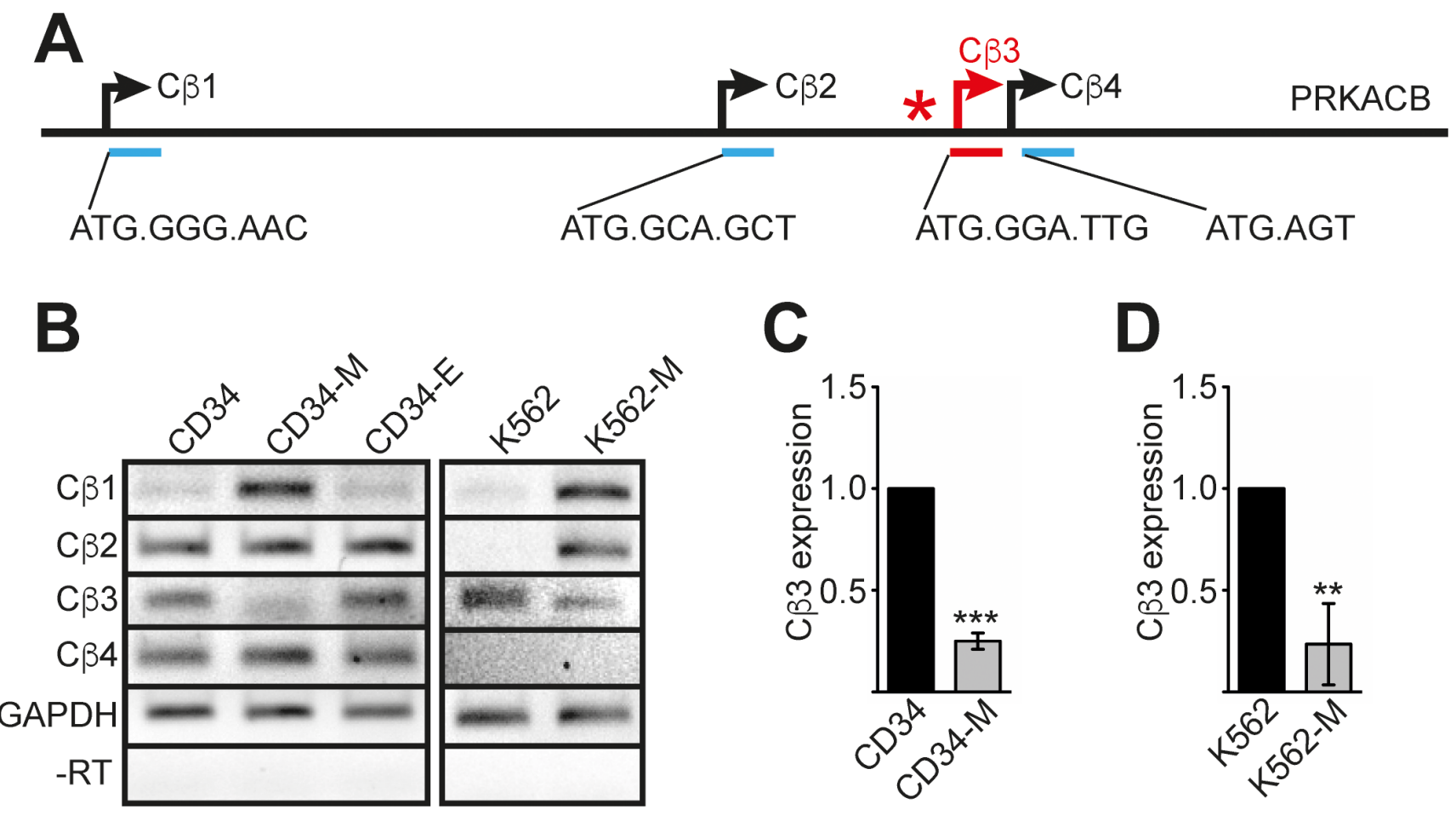

Figure 3: PRKACB isoform expression during differentiation. (A) Schematic overview of the $P R K A C B$ locus. The four promoter regions of the different isoforms are underlined. The first base pairs and the amino acid sequences of the four $P R K A C B$ isoforms $(C \beta 1-C \beta 4)$ are given. (B) Semiquantitative RT-PCR of the different $P R K A C B$ isoforms during CD34+ megakaryocytic (CD34-M) or erythroid (CD34-E) differentiation and TPA-induced megakaryocytic differentiation of K562 cells (K562-M). Expression of GAPDH served as internal control and a -RT control for GAPDH is shown. (C) Quantitative RT-PCR evaluation of C $\beta 3$ expression during megakaryocytic differentiation of human CD34+ cells (CD34-M). (D) Quantitative RT-PCR evaluation of C $\beta 3$ expression during megakaryocytic differentiation of K562 cells (K562-M). Error bars represent the standard deviation of qPCR evaluations of three independent experiments measured in duplicates. $\mathrm{P}$ values were calculated using Student's t-test. $* * * \mathrm{P}<.001$. 


\section{A}
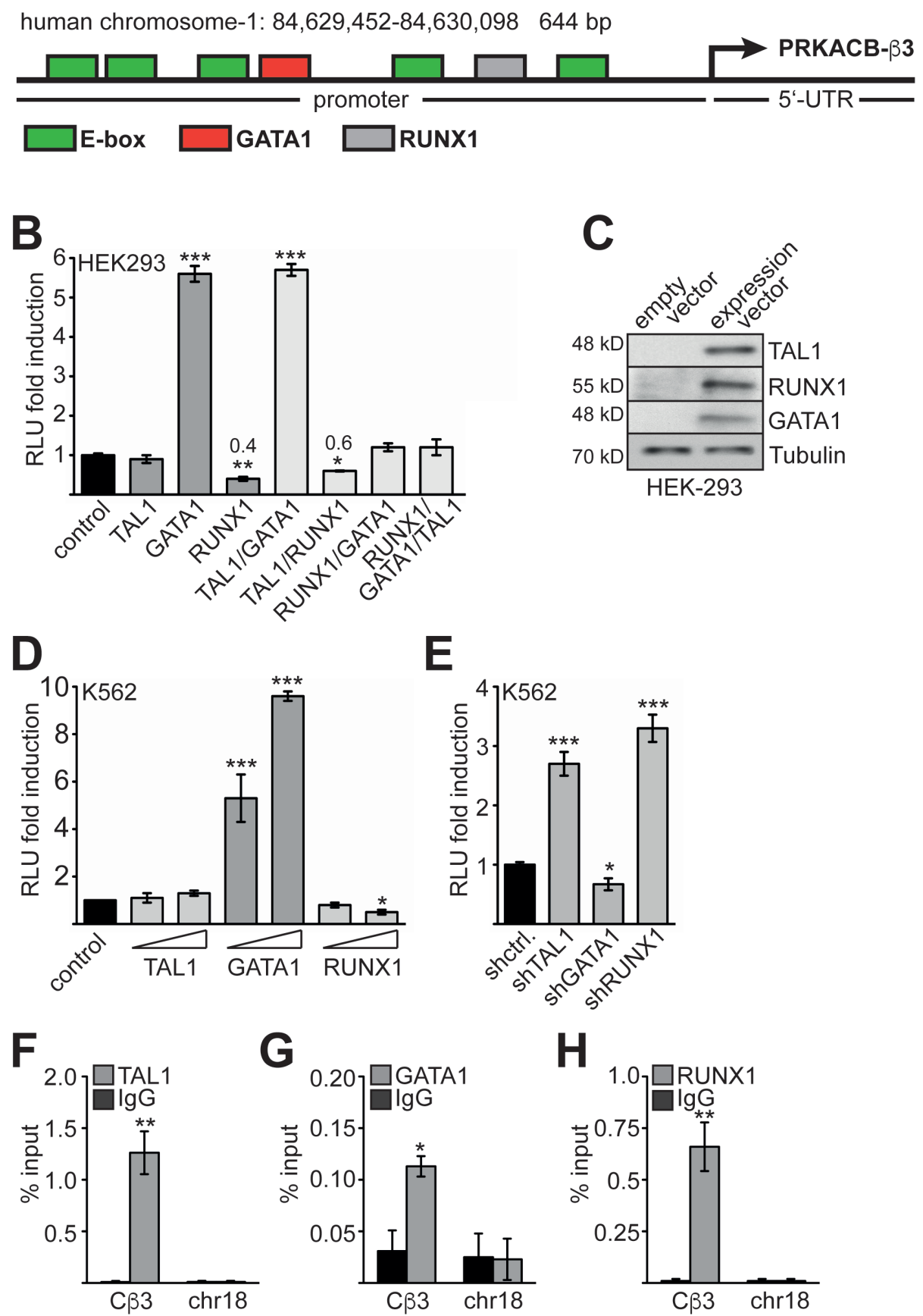

Figure 4: Analysis of the C $\boldsymbol{3} 3$ promoter. (A) Schematic representation of the promoter and 5'-UTR of the human $P R K A C B$ - $C \beta 3$ isoform. The region was cloned in a luciferase vector. Identified potential binding sites for hematopoietic transcription factors and the mRNA start are labelled. (B) Luciferase promoter assay of the $C \beta 3$ promoter in HEK293 cells. Cotransfection of the $C \beta 3$ promoter with transcription factors TAL1, RUNX1 and GATA1. (C) The integrity of the overexpression constructs was verified by western blot. (D) Luciferase promoter assay of the $C \beta 3$ promoter in K562 cells upon overexpression of TAL1, GATA1 and RUNX1, respectively. Raising amounts of expression vectors were transfected. (E) Luciferase promoter assay of the $C \beta 3$ promoter in K562 cells upon knockdown of TAL1, GATA1 and RUNX1, respectively. Luciferase activity was measured two days after transfection. Relative light units (RLU) are given as fold induction compared to the activity of the promoter only (control). (F) ChIP assay showing the binding of TAL1 to the $C \beta 3$ promoter in K562 cells. ChIP-PCR with primers against an unrelated region on chromosome-18 (chr18) serves as negative control. (G) ChIP assay showing the binding of GATA1 to the $C \beta 3$ promoter in K562 cells. ChIP-PCR with primers against an unrelated region on chromosome-18 (chr18) serves as negative control. (H) ChIP assay showing the binding of RUNX1 to the $C \beta 3$ promoter in K562 cells. ChIP-PCR with primers against an unrelated region on chromosome 18 (chr18) serves as negative control. Error bars represent the standard deviation of at least three determinations. The $\mathrm{P}$ values were calculated using Student's t-test. $* \mathrm{P}<.05 ; * * \mathrm{P}<.01 ; * * * \mathrm{P}<.001$. 
Subsequently, we showed by ChIP that TAL1, GATA1 and RUNX1 are present at the PRKACB $\beta 3$ isoform promotor but not to an unrelated region on chromosome-18 (chr18) (Figure 4F-4H).

\section{TAL1, GATA1 and RUNX1 influence endogenous $P R K A C B$ expression}

Because TAL1, GATA1 and RUNX1 play a major role during megakaryocytic differentiation [15] and our data hint towards a role of these transcription factors in regulation of PRKACB, we knocked down the transcription factors by shRNA (Figure 5). TAL1 knockdown (Figure 5A) resulted in increase of overall $P R K A C B$ expression (Figure 5B). The expression of the $C \beta 1$ isoform of $P R K A C B$ was modestly increased about 2- to 4-fold (Figure 5C), whereas expression of the $C \beta 3$ isoform increased substantially (Figure 5D). This result hints towards a repressive function of TAL1 on the expression of the $C \beta 3$ isoform. Given the variation gathered with the different GATA1 shconstructs the knockdown of GATA1 did not alter overall $P R K A C B$ expression and did not significantly change $C \beta 1$ expression (Figure 5E-5G). However, $C \beta 3$ isoform expression was reduced upon GATA1 knockdown (Figure $5 \mathrm{H})$. This is in line with our reporter gene assay showing that GATA1 is an activator of the $C \beta 3$ promoter (Figure 3B, 3D). The knockdown of RUNX1 (Figure 5I) resulted in an overall upregulation of $P R K A C B$ expression (Figure $5 \mathrm{~J})$. Interestingly, expression of $C \beta 1$ was unchanged upon RUNX1 knockdown (Figure 5K), whereas $C \beta 3$ expression was increased (Figure 5L). Taken together, we detected differential effects of TAL1, GATA1 and RUNX1 on $P R K A C B$ isoform expression. Of note, $C \beta 3$ expression was increased by knockdown of TAL1 and RUNX1 indicating a repressive role of these transcription factors. By contrast, GATA1 knockdown reduced $C \beta 3$ expression indicating an activating role of GATA1 on the expression of this isoform.

\section{Cofactor exchange on the $P R K A C B$ promoter upon differentiation}

Transcriptional expression of the $C \beta 3$ isoform of $P R K A C B$ is downregulated during megakaryocytic differentiation. To determine the molecular mechanism underlying this downregulation and the individual contributions of TAL1, GATA1 and RUNX1, we performed ChIP analysis before and after megakaryocytic differentiation of K562 cells. We examined transcription factor binding to the $C \beta 3$ promoter and could detect TAL1 on the $C \beta 3$ promoter before and, less strongly, after megakaryocytic differentiation (Figure 6A). Similarly, GATA1 occupancy was reduced upon megakaryocytic induction (Figure 6B) whereas RUNX1 occupancy was unaffected (Figure 6C). When we induced K562 cells towards megakaryocytic differentiation, we observed an increase of LSD1 occupancy on the $C \beta 3$ promoter (Figure $6 \mathrm{D})$. LSD1 is able to remove methyl residues from lysine 4 of histone 3, and thus counteracts H3K4 methylation by the oncogenic MLL complex. Thus, LSD1 can act as a repressor by decreasing the activating $\mathrm{H} 3 \mathrm{~K} 4 \mathrm{me} 3$ mark on a locus. Concomitantly, binding of WDR5 was strongly reduced (Figure 6E). WDR5 is a central component of the WDR5/MLL complex, which mediates H3K4me3. In parallel, we found reduced levels of the histone acetyltransferase p300 on the promoter (Figure $6 \mathrm{~F})$. Consistent with the changes in histone modifying cofactor occupancy we detected a decrease of the activating histone modifications $\mathrm{H} 3 \mathrm{~K} 9 \mathrm{ac}$ and $\mathrm{H} 3 \mathrm{~K} 4 \mathrm{me} 3$ at the $C \beta 3$ promoter (Figure $6 \mathrm{G}-6 \mathrm{H}$ ) and a concomitant decrease of RNA polymerase II (RNApol-II) occupancy (Figure 6I). To determine if TAL1 contributes to the recruitment of LSD1 to the $C \beta 3$ promoter, we performed a ChIP-Assay upon TAL1 knockdown in K562 cells. The TAL1 knockdown resulted in less TAL1 occupancy (Figure 6J) and contributed to reduced presence of LSD1 (Figure 6K), concomitantly $\mathrm{H} 3 \mathrm{~K} 4 \mathrm{me} 3$ was increased (Figure 6L). This suggests that TAL1 at least partly contributed to LSD1 recruitment in K562 cells. Upon megakaryocytic differentiation the downregulation of $C \beta 3$ expression is triggered by an exchange of an activating cofactor complex containing CBP/p300 and WDR5 with a repressive complex containing increased LSD1 levels.

\section{DISCUSSION}

The transcription factor TAL1 is an important regulator of gene expression at the erythroid/ megakaryocytic branching. To better understand the function of TAL1 at this important differentiation point, we identified target genes of TAL1 using a biotintagged TAL1 in K562 cells. For more detailed analysis we focused on the PRKACB gene, which encodes the catalytic beta subunit of the protein kinase A (PKA). PKAsignalling is important at the megakaryocytic/erythroid branching [39]. Furthermore, it influences downstream transcription factors such as TAL1 $[35,36]$. In particular, we could demonstrate that isoform 3 of PRKACB (CB3) is a direct target gene of the hematopoietic transcription factors TAL1, RUNX1 and GATA1. Interestingly, expression of PRKACB $C \beta 3$ is upregulated during erythroid differentiation and downregulated during megakaryopoiesis. In this respect, $C \beta 3$ behaves like an erythroid gene. Recently, we reported that the transcription factor RUNX1 is a suppressor of erythroid TAL1 target genes such as KLFl and the microRNA miR-144/451 [15, 17]. Similar to this observation, we found that RUNX1 acts as repressor of the PRKACB $C \beta 3$ isoform. On the other hand, our data suggest an activating role of the transcription factor GATA1 on $C \beta 3$ isoform expression. 
A

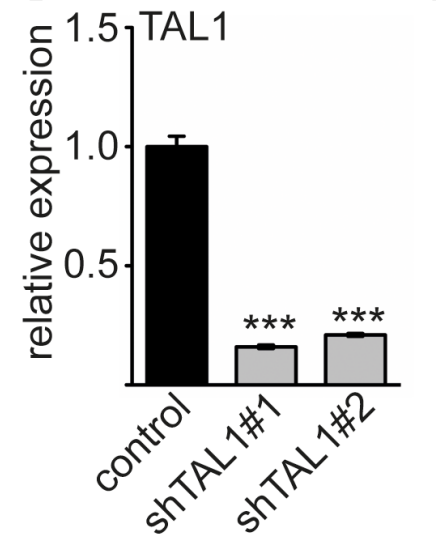

$\mathbf{E}$

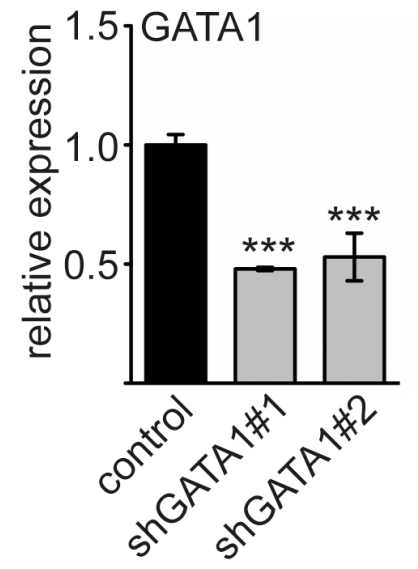

I

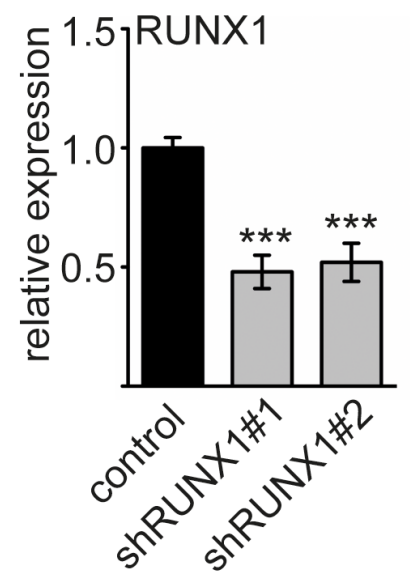

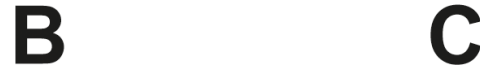
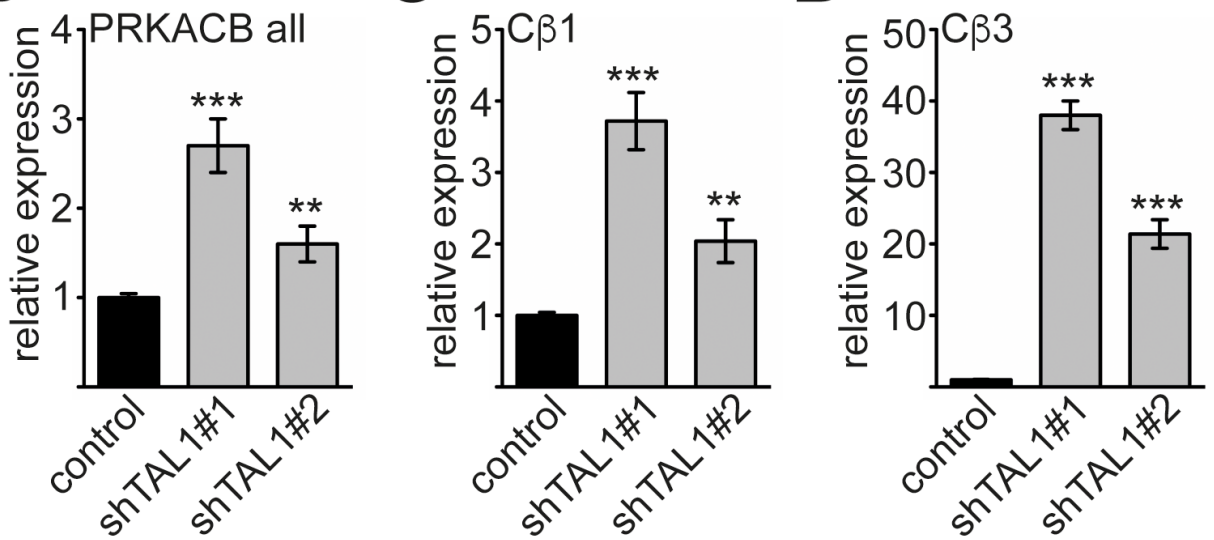

G
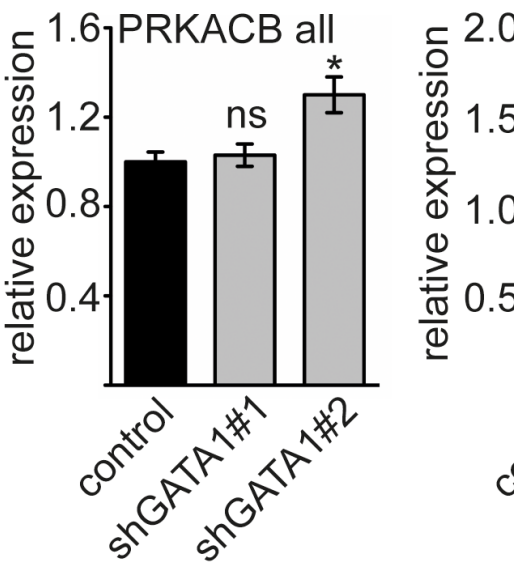

H
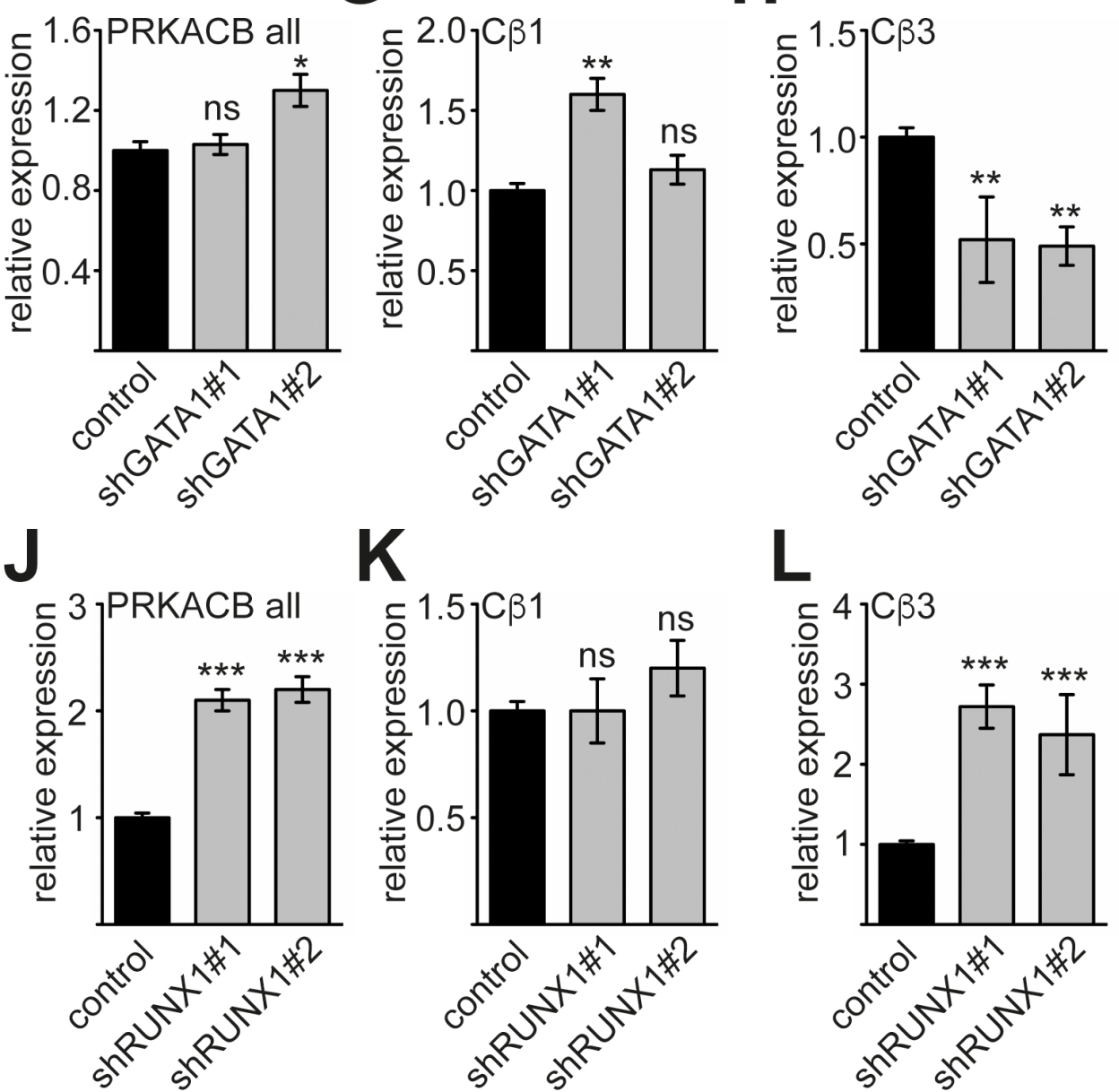

Figure 5: Expression of Cß3 isoform is influenced by TAL1, GATA1 and RUNX1. (A) Knockdown of TAL1 by two different shRNAs measured by qRT-PCR. (B) Overall expression of PRKACB (PRKACB all) upon TAL1 knockdown. (C) Expression of $C \beta 1$ isoform upon TAL1 knockdown. (D) Expression of $C \beta 3$ isoform upon TAL1 knockdown. (E) Knockdown of GATA1 by two different shRNAs measured by qRT-PCR. (F) Overall expression of $P R K A C B$ upon GATA1 knockdown. (G) Expression of $C \beta 1$ isoform upon GATA1 knockdown. (H) Expression of $C \beta 3$ isoform upon GATA1 knockdown. (I) Knockdown of RUNX1 by two different shRNAs measured by qRT-PCR. (J) Overall expression of PRKACB upon RUNX1 knockdown. (K) Expression of $C \beta 1$ isoform upon RUNX1 knockdown. (L) Expression of C $\beta 3$ isoform upon RUNX1 knockdown. Values are shown as relative expression compared to cells transduced with the corresponding vector expressing a non-targeting shRNA labelled as control. Expression of GAPDH served as internal control for normalization of gene expression. The error bars give the standard deviation of at least three evaluations performed in duplicates. The $\mathrm{P}$ values were calculated using Student's t-test. $* \mathrm{P}<.05 ; * * \mathrm{P}<.01 ; * * * \mathrm{P}<.001$. 

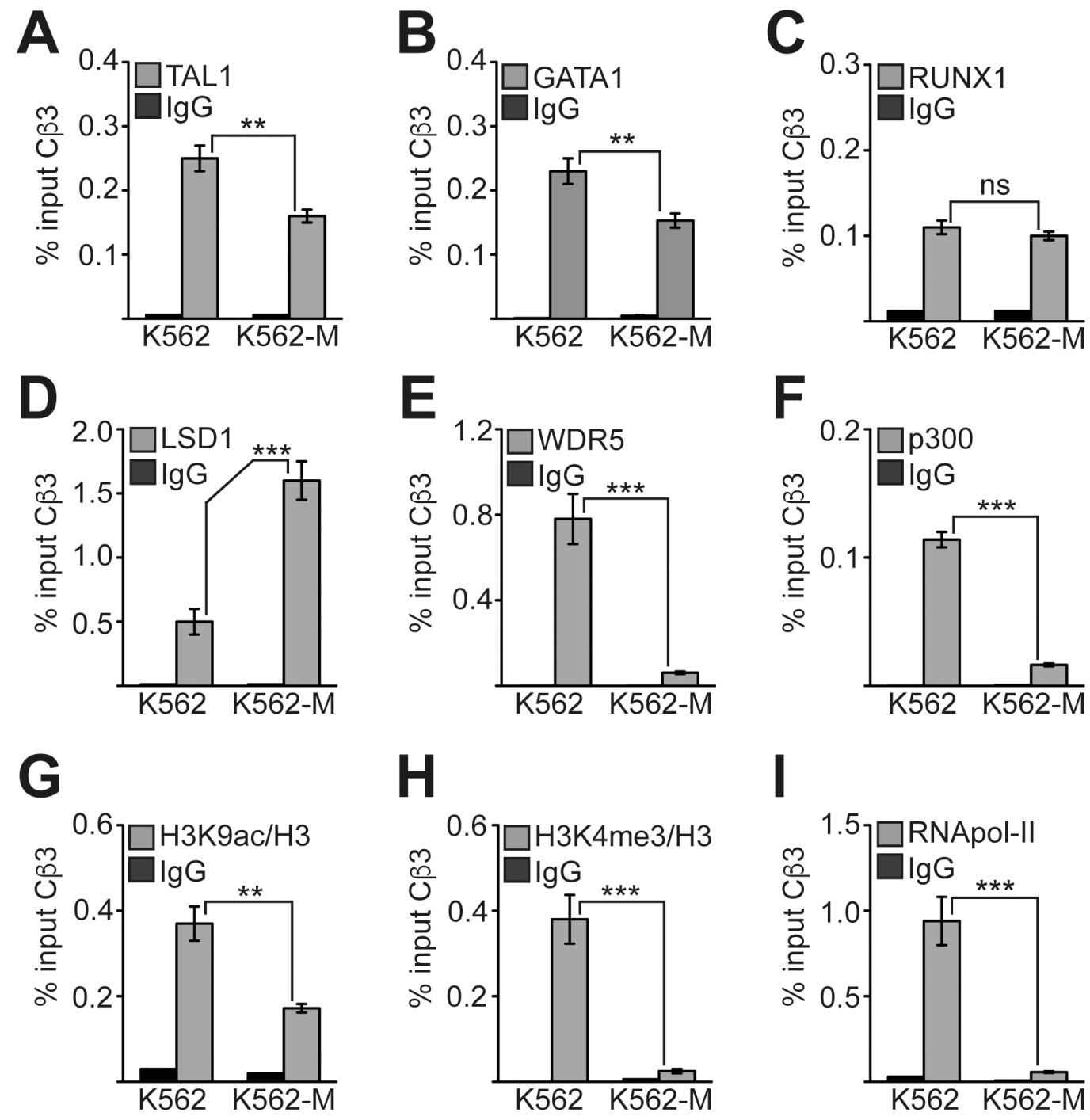

H
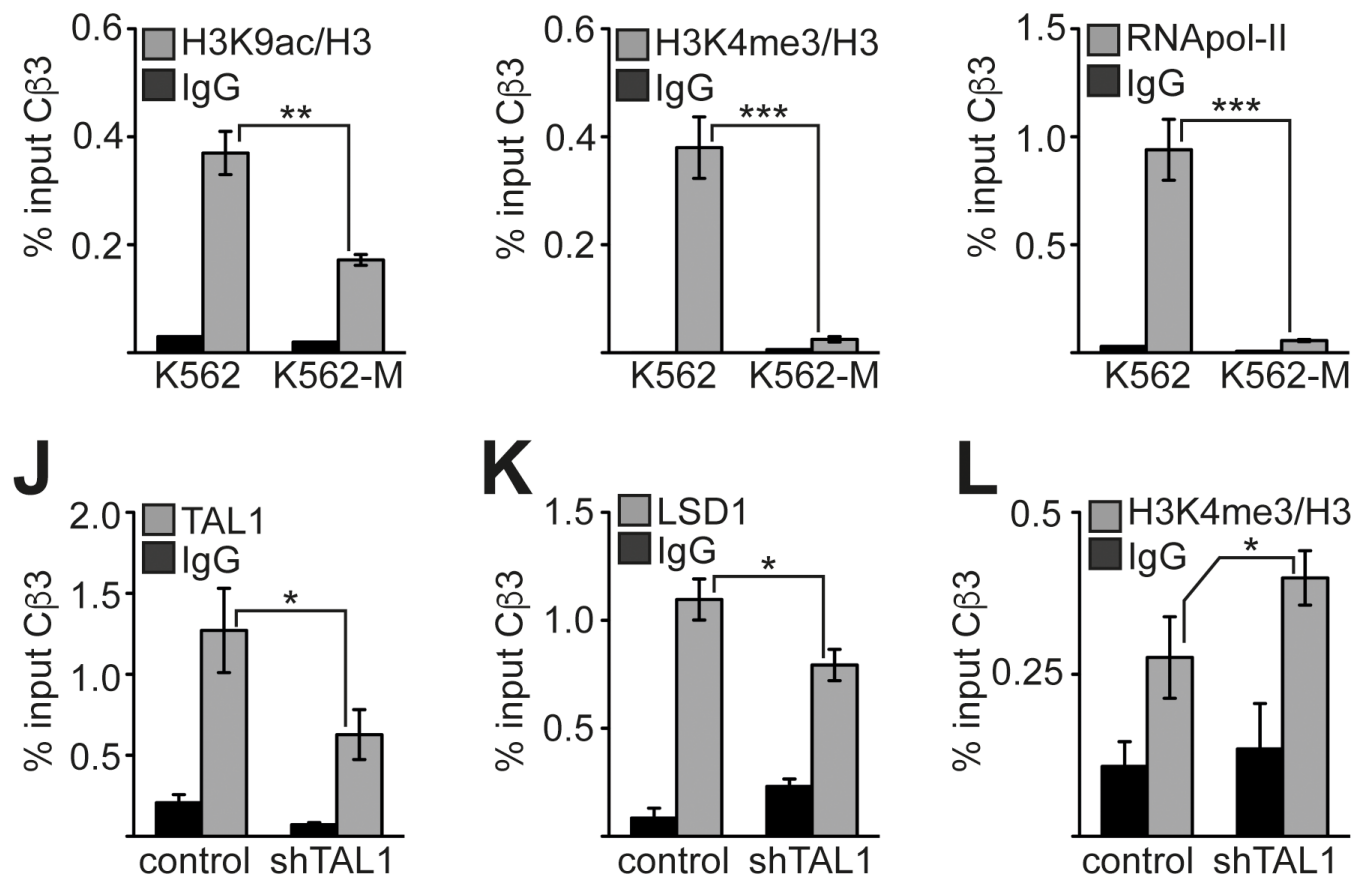

Figure 6: Changes at the $\mathrm{C} \beta 3$ promoter during megakaryocytic differentiation. (A-C) Binding of transcription factors TAL1, GATA1 and RUNX1 to the promoter of C 33 isoform before and after megakaryocytic differentiation of K562 cells induced by TPA. (D-F) Binding of the chromatin modifying cofactors LSD1, WDR5 and p300 to the promoter of $C \beta 3$ isoform before and after megakaryocytic differentiation of K562 cells induced by TPA. (G-H) Measurement of the histone modification status at the $C \beta 3$ promoter. The H3K9ac and $\mathrm{H} 3 \mathrm{~K} 4 \mathrm{me} 3$ status was determined before and after megakaryocytic differentiation of K562 cells induced by TPA. The values were corrected to the histone density according to a ChIP against histone 3 (H3). (I) Binding of RNA-polymerase II (RNApol-II) to the $C \beta 3$ promoter. ChIP was performed with specific antibodies in untreated and TPA-treated (96h) K562 cells. (J) ChIP assay upon TAL1 knockdown. TAL1 binding to the $C \beta 3$ promoter was reduced upon TAL1 knockdown in K562 cells. (K) LSD1 binding to the $C \beta 3$ promoter was reduced upon TAL1 knockdown in K562 cells. (L) H3K4me3 at the CB3 promoter was increased upon TAL1 knockdown in K562 cells. Values are given as percent enrichment compared to the input. Error bars represent the standard deviation of three determinations measured in duplicates. The $\mathrm{P}$ values were calculated using Student's t-test. $* * \mathrm{P}<.01 ; * * * \mathrm{P}<.001$. 
We showed that TAL1, GATA1 and RUNX1 were all already present at the promoter before megakaryocytic specification and remained there during and after differentiation. However, TAL1 and GATA1 binding was decreased upon megakaryocytic differentiation. It had been described that TAL1 and GATA1 can be found together on GATA1/E-box composite elements, which assembles a multiprotein complex with GATA1, LDB1, LMO2, TAL1 and E2A in erythroid cells [4043]. Similarly, GATA1 and RUNX1 have been shown to cooperate during megakaryocytic differentiation on the $\alpha I$ integrin promoter [26]. Furthermore, we recently found that RUNX1 can be a repressor or activator of megakaryocytic genes depending of the differentiation status [37]. Interestingly, RUNX1 and TAL1 are able to directly interact on the erythroid gene $K L F 1$, and during megakaryocytic differentiation epigenetic corepressors are recruited dependent on the presence of RUNX1 [15].

Another observation of ours is that megakaryocytic differentiation is accompanied by a cofactor exchange at the $C \beta 3$ promoter. Decreased $C \beta 3$ expression correlates with reduced presence of the coactivator proteins WDR5 and p300 (Figure 6E-6F). Concomitantly, occupancy of the $C \beta 3$ promoter by the histone lysine demethylase LSD1 increases (Figure 6D). In line with this observation the histone modification pattern changes from an activating state with high $\mathrm{H} 3 \mathrm{~K} 9 \mathrm{ac}$ and $\mathrm{H} 3 \mathrm{~K} 4 \mathrm{me} 3$ to a repressive one with lower $\mathrm{H} 3 \mathrm{~K} 9 \mathrm{ac}$ and loss of H3K4me3 (Figure 6G, 6H). TAL1 was shown to be able to directly recruit LSD1 [44] and thus, might be involved in the recruitment of LSD1 on the $C \beta 3$ promoter. Indeed, knockdown of TAL1 in undifferentiated K562 cells led to decreased LSD1 occupancy and increased H3K4me3 (Figure 6J-6L), showing that TAL1 contributes to repression of $C \beta 3$. Most interestingly, PKA-signalling itself can abolish the association of TAL1 with LSD1 by phosphorylation of serine 172 [36]. This modification destabilizes TAL1-LSD1 interaction and may lead to altered TAL1 DNA binding activity [35]. It is conceivable that TAL1 itself is phosphorylated by cAMP dependent phosphorylation at serine 172 during megakaryopoiesis leading to increased LSD1 recruitment. At present no ChIPgrade TAL1Sp172 specific antibody is available to test this idea at the endogenous protein level. However, other transcription factors, such as RUNX1 or GATA2, are also able to interact with LSD1 and might contribute to LSD1 recruitment [45-47].

Furthermore, downstream of PKA signalling are important transcription factors like cAMP-response element-binding protein (CREB) [48], nuclear factor kappa light chain enhancer of activated B-cells (NF-кB) $[49,50]$, the erythroid nuclear factor 2 (NF-E2) [51], the specificity protein (Sp1) [52] and the activator protein 1 (AP1) [53]. By influencing $P R K A C B$ isoform expression, TAL1, RUNX1 and GATA1 could impact on cAMP signal transduction pathways. This is interesting because cAMP signalling can induce both proliferative and anti-proliferative effects, depending on the cell type $[54,55]$. It is plausible that the relative concentrations of the different isoforms of $P R K A C B$ are a determinant of the context-dependent outcome of cAMP signalling on proliferation. Since TAL1 is associated with increased cell proliferation during erythroid differentiation, it is possible that TAL1 may exert part of its proliferative effect by influencing signalling. Moreover, it was shown that cAMP signalling is implicated in the repression of megakaryocytic differentiation [39]. However, at this time point it is unclear how the distinct PRKACB isoforms influence differentiation. It is conceivable that the altered N-terminus of the different PRKACB isoforms could impact substrate specificities resulting in altered biological functions $[25,56,57]$.

It was also discussed that cAMP signalling plays a role in malignant hematopoiesis [58]. Therefore, our finding that hematopoietic transcription factors, such as TAL1 and RUNX1, influence expression of PRKACB isoforms could connect aberrant transcription factor function with altered PKA signalling in leukemia. This would be supported by the observation that PRKACB regulation by the important oncogene c-Myc is involved in the control of proliferation [59]. Our observations open the possibility of a regulatory loop between transcriptional regulation of $P R K A C B$ isoform expression and the modification status of TAL1 in differentiation and leukemia.

\section{MATERIALS AND METHODS}

\section{Cell culture}

K562 cells (ATCC) were maintained in RPMI with $10 \%$ FCS and $1 \%$ penicillin/streptomycin. To induce megakaryocytic differentiation, K562 cells were treated with $30 \mathrm{nM}$ phorbol 12-o-tetradecanoylphorbol13-acetate (TPA). BirA-K562 cells were established as described [14]. HEK293 cells (ATCC) were cultured in DMEM with $10 \%$ FCS and 1\% penicillin/streptomycin. Mobilized peripheral human primary CD34+ cells were obtained with written informed consent from healthy donors from the Institute for Transfusion Medicine Frankfurt following the ethical guidelines of the Frankfurt University (permit \#329-10 of the Frankfurt University Clinic Ethikkommission). The cells were expanded in vitro under serum-free conditions and subjected to erythroid or megakaryocytic differentiation. Expansion took place for 6 days in StemSpan medium (Stem cell Technologies) supplemented with Flt-3 ligand (100 ng/ml), SCF (100 ng/ $\mathrm{ml})$, IL-3 (20 ng/ml) and IL-6 (20 ng/ml). For erythroid differentiation cells were transferred into StemSpan with SCF (20 ng/ml), IL-3 (5 ng/ml), dexamethasone (2 mM, Sigma), estradiol (0.2 mM, Sigma) and erythropoietin (1 unit/ml, Applichem). For megakaryocytic differentiation cells were treated with SCF $(1 \mathrm{ng} / \mathrm{ml})$, TPO $(30 \mathrm{ng} / \mathrm{ml})$, IL-9 (13.5 ng/ml), and IL-6 (7.5 ng/ml) for 4-6 days [60]. 


\section{Knockdown experiments with shRNA}

Knockdown of TAL1, RUNX1 and GATA1 was achieved with shRNAs present in the pGIPZ vector (Open Biosystems) [17]. The accession numbers of the pGIPZ constructs is given in Supplementary Material. Controls were expressing non-targeting shRNA from the corresponding backbone. Knockdown was verified by qRT-PCR (Figure 5). A corresponding western blot from the same lysates showing the decreased protein amount of TAL1, RUNX1 and GATA1 is shown in [17]. For western blot analysis whole cell extracts from transfected HEK293 cells were used. Proteins were separated using SDS-PAGE and transferred to PVDF membranes. Membranes were blocked with Roti-Block (Carl Roth) and exposed to primary antibody dilution over night at $4^{\circ} \mathrm{C}$. Afterwards membranes were incubated with appropriate secondary antibodies coupled to horseradish peroxidase (HRP) for $1 \mathrm{~h}$ at room temperature. Signals were visualized using Western Super ECL reagent (Pierce) and analysed using $\mathrm{X}$-ray film. Immunoblotting analysis was performed using anti-TAL1 (sc-12984, Santa Cruz), anti-RUNX1 (ab23980, Abcam), anti-GATA1 (sc-1233, Santa Cruz) and anti-Tubulin (ab7291, Abcam).

\section{Reporter gene assay}

The 5'-region of the $C \beta 3$ isoform was amplified from genomic DNA using phusion polymerase (New England Biolabs) and inserted in the luciferase vector pGL4.10 (Promega). Luciferase activity was measured $48 \mathrm{~h}$ after transfection and normalised to the activity of a cotransfected CMV-promoter driven $\beta$-galactosidase vector. Data represent three independent experiments, performed in duplicates. Error bars show the standard deviation. Transfections were performed with metafectene according to the manufacturer's instructions.

\section{ChIP assay}

$1 \times 10^{7} \mathrm{~K} 562$ cells were harvested and resuspended in $10 \mathrm{ml}$ RPMI medium and cross-linked for 15 min with $0.75 \%$ formaldehyde. The cross-link was stopped by adding glycine to a final concentration of $0.125 \mathrm{M}$, the cells were washed with phosphate-buffered saline and lysed in $1.2 \mathrm{ml}$ lysis buffer for $30 \mathrm{~min}$ on ice $(50 \mathrm{mM}$ HEPES-KOH, pH 7.5, $140 \mathrm{mM} \mathrm{NaCl}, 1 \mathrm{mM}$ EDTA, pH 8.0, 1\% Triton X-100, 0.1\% Sodium Deoxycholate, $1 \%$ SDS, protease inhibitors). Chromatin was sheered using a bioruptor sonification device (Diagenode) resulting in fragments with an average of 500 bp length. Subsequently, $450 \mu \mathrm{l}$ RIPA buffer (50 mM Tris, $\mathrm{pH} 8.0$, $150 \mathrm{mM} \mathrm{NaCl}, 2 \mathrm{mM}$ EDTA, pH 8.0, 1\% NP-40, 0.5\% sodium deoxycholate, protease-inhibitors), $5 \mu$ blocked protein-G magnetic beads (Dynabeads Protein G-100, Invitrogen) and 2-10 $\mu$ g antibody (or IgG as control) were added to $150 \mu \mathrm{l}$ of chromatin and incubated over night at $4^{\circ} \mathrm{C}$ on a rotating wheel. One sample was spared for input control. The beads were captured using a magnetic rack and washed three times with wash buffer $(20 \mathrm{mM}$ Tris$\mathrm{HCl}, \mathrm{pH} 8.0,150 \mathrm{mM} \mathrm{NaCl}, 0.1 \%$ SDS, $1 \%$ Triton X-100, 2 mM EDTA, pH 8.0) for 10 min on a rotating wheel at $4^{\circ} \mathrm{C}$ and once with final wash buffer $(20 \mathrm{mM}$ Tris- $\mathrm{HCl}, \mathrm{pH}$ $8.0,500 \mathrm{mM} \mathrm{NaCl}, 0.1 \%$ SDS, $1 \%$ Triton X-100, $2 \mathrm{mM}$ EDTA, $\mathrm{pH}$ 8.0) for $15 \mathrm{~min}$. DNA was eluted using elution buffer (1\% SDS, $\left.100 \mathrm{mM} \mathrm{NaHCO}_{3}\right)$ at room temperature for 15 min with shaking. The cross-link was reversed in $400 \mu \mathrm{l}$ elution buffer with $5 \mu \mathrm{l}$ proteinase $\mathrm{K}(20 \mathrm{mg} /$ $\mathrm{ml}$, Applichem) for 5-6 hours at $65^{\circ} \mathrm{C}$. The DNA was extracted using phenol-chloroform and precipitated over night at $-20^{\circ} \mathrm{C}$ and washed with $70 \%$ ethanol. Antibodies used: anti-RUNX1 from Abcam (ab23980), anti-TAL1 from Abcam (ab75739), anti-PRMT6 from Santa Cruz (sc-55702), anti-p300/CBP from NeoMarkers (MS-586), anti-LSD1 from Abcam (ab17721), anti-WDR5 from Santa Cruz (sc-100895), anti-GATA1 from Santa Cruz (sc1233) and anti-RNApol IIa from Abcam (ab5408). For the ChIP-Assay shown in Figure 4F-4H and Figure 6J-6K the following alternative antibodies were used: anti-GATA1 from Abcam (ab11963), anti-TAL1 from OriGene (GAT, TA590662-OR), anti-RUNX1 from Abcam (ab23980, batch GR275602-1). For chromatin immunoprecipitation of histone modifications antibodies from Abcam were used: anti-H3K9ac (ab10812) anti-H3K4me3 (ab1012) and anti-H3 (ab1791). Primer pairs used for ChIP-PCR are given in Supplementary Material.

\section{Strep-CP}

Streptavidine/biotin-Chromatin-Precipitation (Strep$\mathrm{CP})$ was performed as described [14]. Following Strep-CP, we performed 'Strep-CP on ChIP' analysis using ChIParrays with 12.000 human promoter regions spotted as oligonucleotides [32]. For this, DNA from three independent Strep-CPs were linearly amplified and hybridized to the promoter array. Following intra-array and inter-array normalisation, TAL1 bound sequences were identified by class comparison of BirA-TAL1 cells with the BirAligase only control. 451 promoter sites with TAL1 binding were identified at genes with a high to low statistical likelihood of being target genes of TAL1 (Supplementary File 1). 'Strep-CP on ChIP' data are given. Raw data are given in Supplementary File 1. Genes were subjected to gene ontology (GO-term) analysis using DAVID (DAVID Bioinformatics Resources 6.8) [33, 34]. Parameters for GOterm biological process (GO-BP direct) were default settings (with modified Fisher exact P-value, EASE, set as 0.1).

\section{Quantitative PCR}

Total mRNA was prepared using the RNeasy purification kit (Qiagen) and synthesis of cDNA was performed with omniscript reverse 
transcriptase (Qiagen). Specific primers were used for quantitative RT-PCR. PRKACB (PRKACBforward: 5'-GCCACGACAGATTGGATTG-3'; PRKACB-reverse: 5'-TCCAGAGCCTCTAAAC TTTGGT-3'). For isoform specific PRKACB RTPCR forward primer were designed from the isoform specific 5'-regions and the specific exons and one reverse primer was used for all isoforms $(C \beta 1$-forward: 5'-ACTGTGGAGTGGCGGGCAC-3'; C 32 -forward: 5'-TTGGAAGGTTTTGCTAGCCGGTT-3'; C forward: 5'-TTGCCAGGTTCAACATGGGATT-3', C $\beta 4$ forward: 5'-GGAAAGGTTGGTTTTCATCATG-3'; C $\beta 1$, 2, 3, 4-reverse: 5'-CTGAGTTGGATTCTCCCATTTT-3'). Primer pairs used for qRT-PCR are given in Supplementary Material. Quantitative PCR was performed using SYBRgreen (Eurogentec) and a LightCycler 480 (Roche).

\section{Author contributions}

O.N.K. performed experiments, analysed data and wrote the paper; S.H., A.M, L.S, J.Y. and N.K. performed experiments; H.B. and E.S. provided essential material and guidance; C.M.T. performed experiments and analysed data; J.L. conceived the study, performed experiments, analysed data and wrote the paper.

\section{ACKNOWLEDGMENTS}

We would like to thank Helge Hussong, Stephan Kolodziej, Alexander Piechatzek and Jan Konietzka for assistance.

\section{CONFLICTS OF INTEREST}

The authors have no conflicts of interest to disclose.

\section{FUNDING}

The Deutsche Forschungsgemeinschaft supported this study (SPP-1463, LA1389/5-2).

\section{REFERENCES}

1. Orkin SH, Zon LI. Hematopoiesis: an evolving paradigm for stem cell biology. Cell. 2008; 132:631-44.

2. Teitell MA, Mikkola HK. Transcriptional activators, repressors, and epigenetic modifiers controlling hematopoietic stem cell development. Pediatr Res. 2006; 59:33R-39R.

3. Look AT. Oncogenic transcription factors in the human acute leukemias. Science. 1997; 278:1059-64.

4. Shivdasani RA, Mayer EL, Orkin SH. Absence of blood formation in mice lacking the T-cell leukaemia oncoprotein tal-1/SCL. Nature. 1995; 373:432-34.
5. Mikkola HK, Klintman J, Yang H, Hock H, Schlaeger TM, Fujiwara Y, Orkin SH. Haematopoietic stem cells retain long-term repopulating activity and multipotency in the absence of stem-cell leukaemia SCL/tal-1 gene. Nature. 2003; 421:547-51.

6. Hall MA, Curtis DJ, Metcalf D, Elefanty AG, Sourris K, Robb L, Gothert JR, Jane SM, Begley CG. The critical regulator of embryonic hematopoiesis, $\mathrm{SCL}$, is vital in the adult for megakaryopoiesis, erythropoiesis, and lineage choice in CFU-S12. Proc Natl Acad Sci USA. 2003; 100:992-97.

7. Hall MA, Slater NJ, Begley CG, Salmon JM, Van Stekelenburg LJ, McCormack MP, Jane SM, Curtis DJ. Functional but abnormal adult erythropoiesis in the absence of the stem cell leukemia gene. Mol Cell Biol. 2005; 25:6355-62.

8. Schlaeger TM, Mikkola HK, Gekas C, Helgadottir HB, Orkin SH. Tie2Cre-mediated gene ablation defines the stem-cell leukemia gene (SCL/tal1)-dependent window during hematopoietic stem-cell development. Blood. 2005; 105:3871-74.

9. Bash RO, Hall S, Timmons CF, Crist WM, Amylon M, Smith RG, Baer R. Does activation of the TAL1 gene occur in a majority of patients with T-cell acute lymphoblastic leukemia? A pediatric oncology group study. Blood. 1995; 86:666-76.

10. Ferrando AA, Look AT. Gene expression profiling in T-cell acute lymphoblastic leukemia. Semin Hematol. 2003; 40:274-80.

11. Ferrando AA, Herblot S, Palomero T, Hansen M, Hoang T, Fox EA, Look AT. Biallelic transcriptional activation of oncogenic transcription factors in T-cell acute lymphoblastic leukemia. Blood. 2004; 103:1909-11.

12. Kassouf MT, Hughes JR, Taylor S, McGowan SJ, Soneji S, Green AL, Vyas P, Porcher C. Genome-wide identification of TAL1's functional targets: insights into its mechanisms of action in primary erythroid cells. Genome Res. 2010; 20:1064-83.

13. Wilson NK, Miranda-Saavedra D, Kinston S, Bonadies N, Foster SD, Calero-Nieto F, Dawson MA, Donaldson IJ, Dumon S, Frampton J, Janky R, Sun XH, Teichmann $\mathrm{SA}$, et al. The transcriptional program controlled by the stem cell leukemia gene Scl/Tall during early embryonic hematopoietic development. Blood. 2009; 113:5456-65.

14. Lausen J, Pless O, Leonard F, Kuvardina ON, Koch B, Leutz A. Targets of the Tall transcription factor in erythrocytes: E2 ubiquitin conjugase regulation by Tal1. J Biol Chem. 2010; 285:5338-46.

15. Kuvardina ON, Herglotz J, Kolodziej S, Kohrs N, Herkt S, Wojcik B, Oellerich T, Corso J, Behrens K, Kumar A, Hussong H, Urlaub H, Koch J, et al. RUNX1 represses the erythroid gene expression program during megakaryocytic differentiation. Blood. 2015; 125:3570-79. 
16. Kolodziej S, Kuvardina ON, Oellerich T, Herglotz J, Backert I, Kohrs N, Buscató E, Wittmann SK, Salinas-Riester G, Bonig H, Karas M, Serve H, Proschak E, Lausen J. PADI4 acts as a coactivator of Tall by counteracting repressive histone arginine methylation. Nat Commun. 2014; 5:3995.

17. Kohrs N, Kolodziej S, Kuvardina ON, Herglotz J, Yillah J, Herkt S, Piechatzek A, Salinas Riester G, Lingner T, Wichmann C, Bonig H, Seifried E, Platzbecker U, et al. MiR144/451 Expression Is Repressed by RUNX1 During Megakaryopoiesis and Disturbed by RUNX1/ETO. PLoS Genet. 2016; 12:e1005946.

18. Lécuyer E, Hoang T. SCL: from the origin of hematopoiesis to stem cells and leukemia. Exp Hematol. 2004; 32:11-24.

19. Navarro F, Gutman D, Meire E, Cáceres M, Rigoutsos I, Bentwich Z, Lieberman J. miR-34a contributes to megakaryocytic differentiation of K562 cells independently of p53. Blood. 2009; 114:2181-92.

20. Daniel PB, Walker WH, Habener JF. Cyclic AMP signaling and gene regulation. Annu Rev Nutr. 1998; 18:353-83.

21. Taylor SS, Buechler JA, Yonemoto W. cAMP-dependent protein kinase: framework for a diverse family of regulatory enzymes. Annu Rev Biochem. 1990; 59:971-1005.

22. Skålhegg BS, Landmark BF, Døskeland SO, Hansson V, Lea T, Jahnsen T. Cyclic AMP-dependent protein kinase type I mediates the inhibitory effects of $3^{\prime}, 5^{\prime}$-cyclic adenosine monophosphate on cell replication in human $\mathrm{T}$ lymphocytes. J Biol Chem. 1992; 267:15707-14.

23. Dhanasekaran N, Heasley LE, Johnson GL. G proteincoupled receptor systems involved in cell growth and oncogenesis. Endocr Rev. 1995; 16:259-70.

24. Orstavik S, Reinton N, Frengen E, Langeland BT, Jahnsen T, Skalhegg BS. Identification of novel splice variants of the human catalytic subunit Cbeta of cAMP-dependent protein kinase. European journal of biochemistry/FEBS. 2001; 268:5066-5073.

25. Kvissel AK, Ørstavik S, Øistad P, Rootwelt T, Jahnsen $\mathrm{T}$, Skålhegg BS. Induction of Cbeta splice variants and formation of novel forms of protein kinase A type II holoenzymes during retinoic acid-induced differentiation of human NT2 cells. Cell Signal. 2004; 16:577-87.

26. Elagib KE, Racke FK, Mogass M, Khetawat R, Delehanty LL, Goldfarb AN. RUNX1 and GATA-1 coexpression and cooperation in megakaryocytic differentiation. Blood. 2003; 101:4333-41.

27. Bütler TM, Ziemiecki A, Friis RR. Megakaryocytic differentiation of K562 cells is associated with changes in the cytoskeletal organization and the pattern of chromatographically distinct forms of phosphotyrosylspecific protein phosphatases. Cancer Res. 1990; 50:6323-29.

28. Pencovich N, Jaschek R, Tanay A, Groner Y. Dynamic combinatorial interactions of RUNX1 and cooperating partners regulates megakaryocytic differentiation in cell line models. Blood. 2011; 117:e1-14. https://doi.org/10.1182/ blood-2010-07-295113.

29. Grosveld F, Rodriguez P, Meier N, Krpic S, Pourfarzad F, Papadopoulos P, Kolodziej K, Patrinos GP, Hostert A, Strouboulis J. Isolation and characterization of hematopoietic transcription factor complexes by in vivo biotinylation tagging and mass spectrometry. Ann N Y Acad Sci. 2005; 1054:55-67.

30. van Werven FJ, Timmers HT. The use of biotin tagging in Saccharomyces cerevisiae improves the sensitivity of chromatin immunoprecipitation. Nucleic Acids Res. 2006; 34:e33.

31. Viens A, Mechold U, Lehrmann H, Harel-Bellan A, Ogryzko V. Use of protein biotinylation in vivo for chromatin immunoprecipitation. Anal Biochem. 2004; 325:68-76.

32. Müller-Tidow $\mathrm{C}$, Klein HU, Hascher A, Isken F, Tickenbrock L, Thoennissen N, Agrawal-Singh S, Tschanter P, Disselhoff C, Wang Y, Becker A, Thiede C, Ehninger G, et al, and Study Alliance Leukemia. Profiling of histone H3 lysine 9 trimethylation levels predicts transcription factor activity and survival in acute myeloid leukemia. Blood. 2010; 116:3564-71.

33. Huang W, Sherman BT, Lempicki RA. Systematic and integrative analysis of large gene lists using DAVID bioinformatics resources. Nat Protoc. 2009; 4:44-57.

34. Huang da W, Sherman BT, Zheng X, Yang J, Imamichi T, Stephens R, Lempicki RA.Extracting biological meaning from large gene lists with DAVID. Curr Protoc Bioinformatics. 2009; Chapter 13:Unit 13.11.

35. Prasad KS, Brandt SJ. Target-dependent effect of phosphorylation on the DNA binding activity of the TAL1/ SCL oncoprotein. J Biol Chem. 1997; 272:11457-62.

36. Li Y, Deng C, Hu X, Patel B, Fu X, Qiu Y, Brand M, Zhao K, Huang S. Dynamic interaction between TAL1 oncoprotein and LSD1 regulates TAL1 function in hematopoiesis and leukemogenesis. Oncogene. 2012; 31:5007-18.

37. Herglotz J, Kuvardina ON, Kolodziej S, Kumar A, Hussong H, Grez M, Lausen J. Histone arginine methylation keeps RUNX1 target genes in an intermediate state. Oncogene. 2013; 32:2565-75.

38. Schug J. Using TESS to predict transcription factor binding sites in DNA sequence. Curr Protoc Bioinformatics. 2008; Chapter 2:Unit 2.6. https://doi.org/10.1002/0471250953. bi0206s21.

39. Rubinstein JD, Elagib KE, Goldfarb AN. Cyclic AMP signaling inhibits megakaryocytic differentiation by targeting transcription factor 3 (E2A) cyclin-dependent kinase inhibitor 1A (CDKN1A) transcriptional axis. J Biol Chem. 2012; 287:19207-15.

40. Lahlil R, Lécuyer E, Herblot S, Hoang T. SCL assembles a multifactorial complex that determines glycophorin $\mathrm{A}$ expression. Mol Cell Biol. 2004; 24:1439-52. 
41. Wadman IA, Osada H, Grütz GG, Agulnick AD, Westphal $\mathrm{H}$, Forster A, Rabbitts TH. The LIM-only protein Lmo2 is a bridging molecule assembling an erythroid, DNA-binding complex which includes the TAL1, E47, GATA-1 and Ldb1/ NLI proteins. EMBO J. 1997; 16:3145-57.

42. Vyas P, McDevitt MA, Cantor AB, Katz SG, Fujiwara Y, Orkin SH. Different sequence requirements for expression in erythroid and megakaryocytic cells within a regulatory element upstream of the GATA-1 gene. Development. 1999; 126:2799-811.

43. Xu Z, Huang S, Chang LS, Agulnick AD, Brandt SJ. Identification of a TAL1 target gene reveals a positive role for the LIM domain-binding protein Ldb1 in erythroid gene expression and differentiation. Mol Cell Biol. 2003; 23:7585-99.

44. Hu X, Li X, Valverde K, Fu X, Noguchi C, Qiu Y, Huang S. LSD1-mediated epigenetic modification is required for TAL1 function and hematopoiesis. Proc Natl Acad Sci USA. 2009; 106:10141-46.

45. van Riel B, Pakozdi T, Brouwer R, Monteiro R, Tuladhar K, Franke V, Bryne JC, Jorna R, Rijkers EJ, van Ijcken W, Andrieu-Soler C, Demmers J, Patient R, et al. A novel complex, RUNX1-MYEF2, represses hematopoietic genes in erythroid cells. Mol Cell Biol. 2012; 32:3814-22.

46. Guo Y, Fu X, Jin Y, Sun J, Liu Y, Huo B, Li X, Hu X. Histone demethylase LSD1-mediated repression of GATA-2 is critical for erythroid differentiation. Drug Des Devel Ther. 2015; 9:3153-62.

47. Guo Y, Fu X, Huo B, Wang Y, Sun J, Meng L, Hao T, Zhao ZJ, Hu X. GATA2 regulates GATA1 expression through LSD1-mediated histone modification. Am J Transl Res. 2016; 8:2265-74.

48. Gonzalez GA, Montminy MR. Cyclic AMP stimulates somatostatin gene transcription by phosphorylation of CREB at serine 133. Cell. 1989; 59:675-80.

49. Zhong H, Voll RE, Ghosh S. Phosphorylation of NF-kappa B p65 by PKA stimulates transcriptional activity by promoting a novel bivalent interaction with the coactivator CBP/p300. Mol Cell. 1998; 1:661-71.

50. Takahashi N, Tetsuka T, Uranishi H, Okamoto T. Inhibition of the NF-kappaB transcriptional activity by protein kinase A. European journal of biochemistry/FEBS. 2002; 269:4559-4565.

51. Casteel D, Suhasini M, Gudi T, Naima R, Pilz RB. Regulation of the erythroid transcription factor NF-E2 by cyclic adenosine monophosphate-dependent protein kinase. Blood. 1998; 91:3193-201.

52. Rohlff C, Ahmad S, Borellini F, Lei J, Glazer RI. Modulation of transcription factor $\mathrm{Sp} 1$ by cAMPdependent protein kinase. J Biol Chem. 1997; 272:21137-41.

53. de Groot RP, Sassone-Corsi P. Activation of Jun/AP-1 by protein kinase A. Oncogene. 1992; 7:2281-86.

54. Zachary I, Masters SB, Bourne HR. Increased mitogenic responsiveness of Swiss 3T3 cells expressing constitutively active Gs alpha. Biochem Biophys Res Commun. 1990; 168:1184-93.

55. Chen J, Iyengar R. Suppression of Ras-induced transformation of NIH 3 T3 cells by activated G alpha s. Science. 1994; 263:1278-81.

56. Niyitegeka JM, Bastidas AC, Newman RH, Taylor SS, Ongeri EM. Isoform-specific interactions between meprin metalloproteases and the catalytic subunit of protein kinase A: significance in acute and chronic kidney injury. Am J Physiol Renal Physiol. 2015; 308:F56-68.

57. Søberg K, Jahnsen T, Rognes T, Skålhegg BS, Laerdahl JK. Evolutionary paths of the cAMP-dependent protein kinase (PKA) catalytic subunits. PLoS One. 2013; 8:e60935.

58. Boer AK, Drayer AL, Vellenga E. cAMP/PKA-mediated regulation of erythropoiesis. Leuk Lymphoma. 2003; 44:1893-901.

59. Wu KJ, Mattioli M, Morse HC 3rd, Dalla-Favera R. c-MYC activates protein kinase A (PKA) by direct transcriptional activation of the PKA catalytic subunit beta (PKA-Cbeta) gene. Oncogene. 2002; 21:7872-82.

60. Mahajan MC, Karmakar S, Newburger PE, Krause DS, Weissman SM. Dynamics of alpha-globin locus chromatin structure and gene expression during erythroid differentiation of human CD34(+) cells in culture. Exp Hematol. 2009; 37:1143-1156.e3. 